\title{
Does Divine Intervention Violate Laws of Nature?
}

\author{
Ralf B. Bergmann*
}

Received: 13 July 2018 / Accepted: 29 November 2018

Abstract: The present paper discusses processes in our world embedded in a dense net of causes and effects. The role of laws of nature is discussed using classical mechanics as an example to demonstrate that the behavior of objects is not determined by laws of nature on their own. Natural processes rather depend on the environment that implies forces and conditions under which these processes occur. These conditions are usually described in mathematical terms using suitable initial or boundary conditions or further constrains. This analysis may seem trivial but has an important consequence. Divine intervention appears not to violate natural laws, rather, new causes are introduced that lead to results that otherwise would not have occurred. A further consequence arises from the complexity of causal nets and the presence of probabilistic processes in our world as one may not be able to determine the causes that led to a certain effect.

Keywords: Causation; causal processes; probabilistic processes; laws of nature; equations of motion; divine action; miracles.

* University of Bremen

Faculty of Physics and Electrical Engineering, University of Bremen, Otto Hahn Allee NW1, 28359 Bremen, Germany

$\bowtie$ Ralf.Bergmann@uni-bremen.de

(C) The Author. Journal compilation (C) The Editorial Board, Organon F.

This article is distributed under the terms of the Creative Commons Attribution-NonCommercial 4.0 International Public License (CC BY-NC 4.0). 


\section{Introduction: the claim of causal closure}

Many contemporary physicists, philosophers and theologians would argue that a God or other transcendent entities, given such entities exist, would not be able to intervene in the physical world, because every event is determined by physical processes that are governed by the laws of nature. Although this thinking has a long tradition, the meaning, the basis and the consequences of this statement, often referred to as causal closure, are often rather diffuse and widely differ amongst and within various disciplines. If this reasoning was correct, there would be no room for divine intervention of whatever kind. Most obviously, there would be no room for miracles.

The protestant theologian Friedrich Schleiermacher (1768-1834) redefined the term miracle as a mere description of events that have a somehow religious relevance, however common the event may appear. ${ }^{1}$ Ludwig Feuerbach (1804-1872) well known for his critique on religion, describes the term miracle as something that is unthinkable and is in the end a meaningless concept (Feuerbach 2016, 125). Feuerbach's statement is, however, an a priori assumption rather than an argument. Perhaps one of the most influential modern protestant theologians arguing on the matter is Rudolf Bultmann (1884-1976). Although his viewpoint and that of his followers was never undisputed, ${ }^{2}$ his views are still quite influential and widespread and offer a reasonably clear, though weak reasoning for his case (Bultmann 1960). In his famous essay entitled "Neues Testament und Mythologie" (New Testament and Mythology) he expresses the idea, that the miracles described in the New Testament cannot be taken as reports of historic events, "because experience and application of science and technology have progressed so far, that no man can and does seriously stick to the world view of the New Testament." ${ }^{3}$ He concludes that by the knowledge of the powers

1 For a compact source see (Schleiermacher 1969, 79), as reference for theologians (von Meckenstock 2011) is usually employed.

2 See e.g. (C. S. Lewis 1947) for a popular version of criticism or (Wilckens 2017) for a theologically based criticism of Bultmann's approach.

3 Translation of the author from (Bultmann 1960). A slightly shortened but easier accessible source of his paper is (Härle 2007, 174-88). 
and laws of nature there is no room left for transcendent intervention and that humans are not open to the influence of "foreign" powers. Due to the philosophical and theological significance of causal closure implied by the statements of Bultmann and others and the claim of the impossibility of divine intervention, there was and is a longstanding and controversial debate [see e.g. (Mackie 1982)] that presently seems to undergo a revival [see e.g. (Keener 2011), (Larmer 2014) and (von Wachter 2015)]. For a philosophic discussion of various views on divine agency and definitions of miracles see e.g. (Larmer 2014, 7-52).

In this paper I will argue, that causal closure does not follow from physics but rather is a metaphysical principle. I will then investigate the nature of laws of physics and argue, that these laws in themselves do not determine physical processes. In what follows, classical mechanics serves as an example to demonstrate that the equations of motion describing the actual movement of a body are determined not only by natural laws but also by initial and boundary conditions or further constraints. This observation, although clear to every physicist, has a profound impact on the question, whether divine intervention violates laws of nature.

\section{Causal networks and laws of nature}

\subsection{The clockwork universe}

Before the arrival of quantum mechanics in the beginning of the $20^{\text {th }}$ century, the universe was frequently conceived as of a kind of clockwork: The history of the universe and all its parts correspond to the functioning of a perfect clockwork. The development of the world is fully determined and can thus - at least in principle - be fully calculated once one knows the laws of nature and the state of the universe at one time. Past and future of the universe can be exactly calculated. For an imaginary being, the so called "Laplacian Demon" (Laplace 1814), capable of knowing and calculating all these details, nothing would come as a surprise.

Figure 1 shows a simple scheme of cause and effect. For the sake of simplicity, I will restrict the discussion at this point to processes related to classical mechanics: The movement or the status of an object (circle) is 
changed by some effects (squares) at various points in time. The movement or change of the object can be calculated if one knows the initial conditions and the forces acting on the object, see Fig. 1a and b. Up to this point, the scheme only shows the basic building blocks of the clockwork universe. But there is already a problem at the first cause, see Fig. 1c: Every description in terms of physics needs a starting point, from which the following process can be calculated. The "first cause" is outside the realm of physics, see the bright square at the far left of Fig. 1 c. There is, contrary to frequently made claims even by physicists [see e.g. (Hawking 2010) and (Krauss 2012)], no way to explain "something" from "nothing" [see e.g. (Craig 2002) or (Bussey 2013)].

Figure 2 sketches a scenario that much more resembles the real world than Figure 1: In the real world many processes happen simultaneously and influence each other as indicated in Fig. 2a. Apart from the first starting point (bright squares), we now have the deterministic picture of a clockwork universe. But in the real world other factors enter in as depicted in Fig. 2b: Besides deterministic processes, there are processes that bring in an element of chance (indicated by dices). These processes are a consequence of quantum mechanics ${ }^{4}$ and deterministic chaos. ${ }^{5}$ Quantum mechanics only describes the probabilities that can be expected for the outcome of an experiment and probabilistic behavior appears to be immanent in nature. ${ }^{6}$ Deterministic chaos, on the other hand, describes the behavior of systems based on classical mechanics ${ }^{7}$ that reacts strongly on

4 For a basic introduction to quantum mechanics see e.g. (Giancoli 2010, chap. $39)$.

5 For an introduction on deterministic chaos see e.g. (Alligood 2009).

${ }_{6}$ Although the formalism of quantum mechanics is extremely successful in precisely calculating observable phenomena, its very nature is still under heavy debate, for details see e.g. (Ney 2013).

7 Apart from deterministic chaos, it has been debated that determinism fails in classical mechanics anyway as argued e.g. by the example of Norton's dome, see e.g. (Norton 2008). Norton shows that a point mass located on the apex of a dome-like surface in a gravitational field may either stay at rest or spontaneously move down the surface after an undetermined amount of time. Due to its' several idealizationsespecially that of a point mass - this case represents by far no realistic scenario and the validity of the case has been heavily questioned and lead critics to the question 
(a)

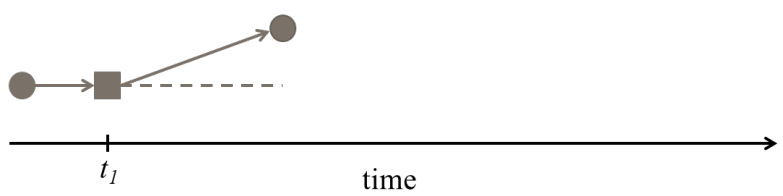

(b)
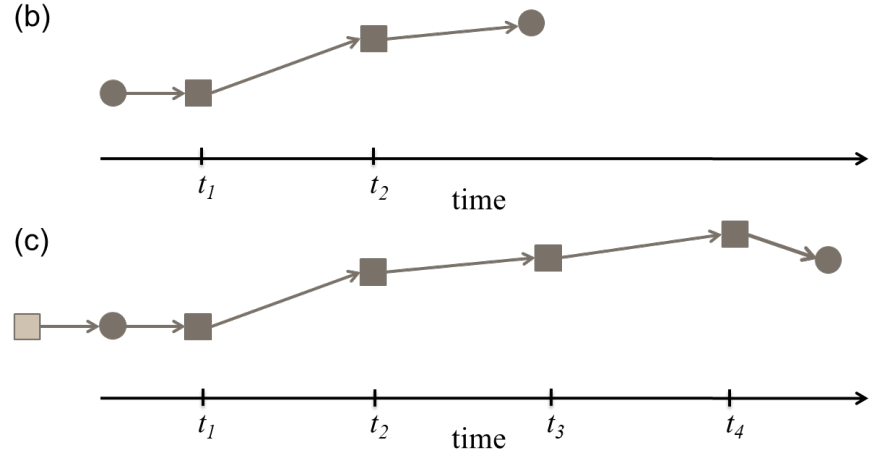

Figure 1: An object (sphere) moves from left to right on the axis of time. a) At time $t_{1}$ there is a cause (square) that changes the direction of the object. b) At time $t_{2}$ another cause results in another change of direction. c) At further points in time $t_{3}, t_{4}$ etc. there are further effects causing further changes of the movement of the object. The first cause (bright square to the left), however, cannot be explained in terms of physics, since a physical description requires initial and / or boundary conditions and the existence of suitable laws to start with. (O) R. B. Bergmann, Bremen, 2018.

minute changes of initial or boundary conditions. A well-known example is the daily weather pattern. The fact that weather cannot be predicted reliably over longer periods of time (say more than two weeks) is due to

of the metaphysical implications of such idealizations (Laraudogoitia 2013). Dantas just recently suggested a description that tries to adjust to a more realistic scenario. However, she leaves open the question of "what constitutes the fundamental (not only operational) conditions for establishing valid Newtonian systems, if there are any such conditions at all" (Dantas 2018). Although Newtonian mechanics is in many cases a good approximation for settings in the real world, the example makes abundantly clear that it is only an idealization! 
(a)

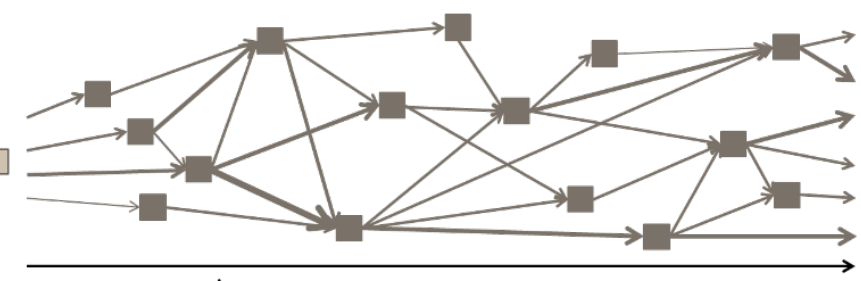

time

(b)

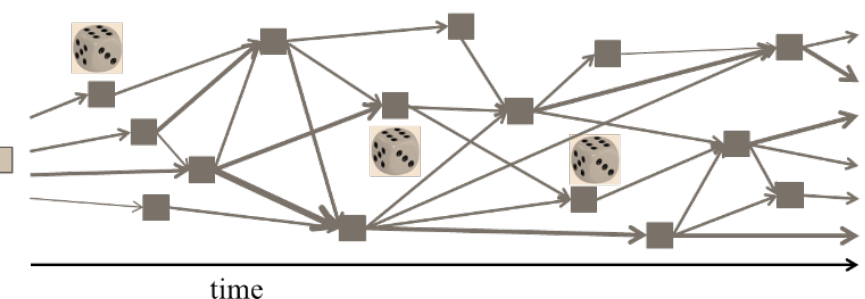

(c)

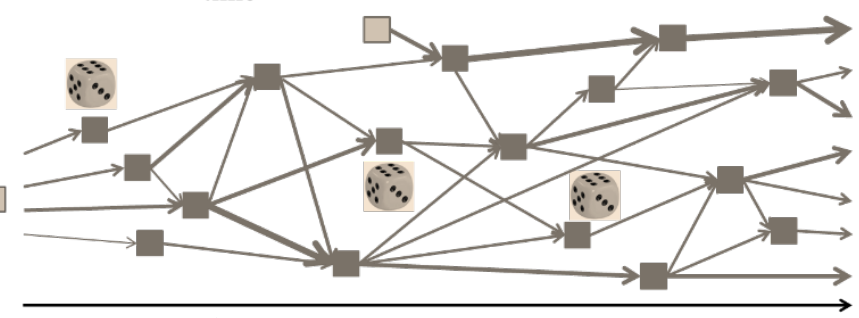

time

Figure 2: In the real world many processes happen simultaneously and interact with each other (for simplification, the objects which are influenced are omitted in contrast to Fig. 1.) a) The clockwork universe: Dark squares depict a network of processes interacting in a fully deterministic way upon each other. Bright square: First cause. b) The dices indicate the action of processes that incorporate probabilities c) Bright square at the top in the center of the drawing indicates divine intervention that changes or extends the existing net of causes and effects. (C) R. B. Bergmann, Bremen, 2018.

just this type of behavior and cannot be overcome even by the most powerful computers (or more powerful computers to come). I leave a discussion on the conditions and details of these phenomena to the literature, as the mechanisms described above suffice for the purpose of the present 
paper. Consequently, the clockwork universe is a fiction and the Laplacian demon is dead! ${ }^{8}$

Finally, I will extend the view developed so far by taking into account divine intervention, see Fig. 2c. In this simple picture, divine intervention introduces another cause into the causal network that alters the previously existing flow of cause and effects or brings about new effects (see the bright square in the upper middle).

\subsection{Natural laws and equations of motion}

Is divine intervention in contradiction with laws of nature? In order to answer this question, we will have to have a look as to what we call a law of nature and what these laws can predict. It is obvious that we would like a law of nature to be valid in a large variety of situations. As we do not have a "theory of everything" with the one law that describes all aspects of physics, we must content ourselves with the most general laws valid for a broad range of situations. In addition, there is usually not just one single law but a set of laws that is needed to describe a certain physical context, e.g. Newton's laws for classical mechanics or Maxwell's equations for classical electrodynamics. ${ }^{9}$

For the sake of intuitive clarity and simplicity, I will use classical mechanics as it was established by Isaac Newton and others as an example here. Take the law that states the gravitational force between two masses $M$ and $m$ (say the mass of the earth $M$ and the mass of a satellite $m$ ) given by

$$
F_{G}=\frac{G}{r^{2}} M m
$$

\footnotetext{
8 It wouldn't help trying to keep the Laplacian Demon alive by arguing that he would know all the initial conditions exactly and has unlimited computational power, since the accuracy of the knowledge of initial conditions is finally limited by Heisenberg's uncertainty principle.

9 The basics of classical mechanics are described e.g. in (Giancoli 2010, chaps. 48) and the Maxwell equations as the basis for classical electrodynamics are e.g. described in (Giancoli 2010, chap. 32).
} 
with the gravitational constant $G$ and the distance $r$ between them. ${ }^{10}$ Whether we obtain a movement of the satellite e.g. revolving around the earth or falling on the earth, depends on the initial condition of the problem. Here, the initial condition describes the final velocity and direction the satellite is given by his propulsion system at the end of its launch. For other problems, imagine a vibrating string of a musical instrument, we further need boundary conditions, e.g. given by the fact that the string is tightly fastened at both ends.

To calculate the movement of a body with mass $m$ under the influence of a force $F$ one uses the well-known equation

$$
F=m a
$$

from classical mechanics. The first step to determine the acceleration $a$ of the body is to determine, which force $F$ acts on it. It may be the gravitational force of Eq. (1), but it may also be another force or a superposition of several forces. Once we know all forces, and thus the resulting force $F$, we can write down the equation of motion. In a second step we need to know the initial conditions and for problems with two or three dimensions we also need to know the boundary conditions employed. Thus, natural laws don't come on their own but always need a context!

As a first result, we can state that the question whether a natural law on its own determines the motion of a body is "no." This result is in accord for example with much of the reasoning of von Wachter (2015) and will be further developed here.

To illustrate the situation, let us look at a very simple situation: If you drop an apple from a certain height one can calculate how it moves towards the ground and what speed it will reach, when it touches the ground. To solve this problem, we first have to determine the equation of motion. For

10 Equation (1) is, however, only an idealized case for two point-masses and their gravitational attraction. For maximum simplification, I have also only introduced the scalar expression here in order to avoid further complications by using a vector notation. I also assume the masses not to be too small or two large and moving with a relative speed much smaller than the speed of light in order to avoid quantum mechanical or relativistic effects. 
this purpose, we need to know the force that acts on the apple. This force is, close to the surface of the earth, given by

$$
F_{g}=-m g
$$

with the earth's acceleration constant $g=9.81 \mathrm{~m} / \mathrm{s}^{2}$. (The minus sign is only a technical detail arising from the force being directed towards the ground.) To obtain the equation of motion, we equate the forces in Eq. (2) and Eq. (3) and obtain $m a=-m g$ or simply

$$
a=-g
$$

which results in the equation of motion represented by the ordinary differential equation

$$
\frac{d^{2} x(t)}{d t^{2}}=-g
$$

with the height of the apple $x(t)$ as function of time $t$.

In the second step, we must apply the initial conditions of the movement to Eq. (5) in order to calculate a specific solution and thus to obtain the trajectory of the apple. Assume you drop the apple from a height $h$ then this is one of the initial conditions necessary to calculate the actual movement. If you just dropped the apple without giving it an extra initial velocity, then the second initial condition is the starting velocity of $v_{0}=0$. If you would, however, choose to throw the apple upwards with an initial velocity of $v_{0}>0$, the movement of the apple will obviously be different.

Solving Eq. (5) for the first case with the starting velocity of $v_{0}=0$ at the time $t_{0}=0$, the movement of the apple follows

$$
x(t)=h-1 / 2 g t^{2}
$$

until it reaches the ground at $x=0$. If you decide not just to drop the apple, but toss it up with a velocity $v_{0}>0$, the solution is given by

$$
x(t)=h-1 / 2 g t^{2}+v_{0} t
$$

until it touches the ground at $x=0$.

The way the apple moves in a specific situation is therefore not only determined by the corresponding natural laws, but also by the special conditions applied. 
We now see that influencing natural (mechanical) processes does not violate laws of nature but only change the corresponding equation of motion or the solution of the corresponding equation of motion. At a later stage of this paper, I will apply this concept - that appears to be quite natural in the context of human action - to divine intervention.

\subsection{Conservation of energy, invariance and symmetry}

Before we come to the question of divine intervention, I want to discuss a commonly raised objection: Does divine intervention contradict the principle of energy conservation? In order to clarify this question, we need to look a little bit deeper into the idea of energy conservation. As e.g. Larmer (2009) points out, energy conservation can be defined in different ways. One way is to state that "Energy can neither be created nor destroyed," the second way is to state that "in an isolated system the total amount of energy remains constant." These two statements are, however, not equivalent, as the second can be deduced from the first, but the first cannot be deduced from the second. The second statement can be empirically tested and appears to be experimentally well justified. The first one cannot be tested and appears to be a metaphysical principle. Therefore, it appears reasonable to stick to the empirically well-established principle that the total amount of energy in an isolated system remains constant.

How can we then deal with a situation in which an entity from outside interacts with the system? In this case the system is obviously not isolated (or closed) any more. Usually, one deals with non-isolated systems by equating the change of the energy within the system with the difference of the flow of energy into or out of the system. Who or whatever interacts with a system has somehow to supply the energy required to bring about the observed effect. For the system or object to be influenced, it does not matter where the energy is coming from. Nature just follows its laws in combination with the applied forces, initial and boundary conditions or whatever constraints involved. ${ }^{11}$

11 It has frequently been speculated that biological systems and especially the human brain is susceptible to quantum mechanical influences involving only a minute amount of energy or even zero energy. One of the earlier ideas were described by Popper and Eccles, see e.g. (Eccles 1994). Such mechanisms may allow mind-body 
In order to gain a deeper understanding of the concept of energy conservation, I want to point out that energy conservation is not only an empirically well-established concept, but is related to certain types of symmetries and invariances. To discover theses relations, one must use an alternative approach to Newtonian mechanics, the so-called Hamilton-Lagrange-formalism. ${ }^{12}$ The interesting aspect of this approach is that it allows in addition to the calculation of equations of motion also to determine which quantities are conserved. Conservation is not limited to energy but may also apply to other quantities and is related to corresponding symmetries and invariances.

Table 1 gives the most prominent examples of the conservation of quantities in the context of classical mechanics and their related symmetries and invariances. ${ }^{13}$ The fact that, in the framework of classical mechanics, the same experiment carried out under the same conditions at different times $t_{1}$ and $t_{2}$ leads to the same result reflects the homogeneity of time and therefore energy conservation. If, however, experimental conditions between times $t_{1}$ and $t_{2}$ change, e.g. by an external intervention, the situation is not any more invariant against translation in time and the energy involved in the experiment at the two points in time can of course well be different. As can be seen from this simple example, conservation of energy as a consequence of symmetries and invariances cannot safeguard against the possibility of external intervention of whatever kind but rather relies on unchanged experimental conditions between different points in time. This argument of course also holds for the other quantities stated in table $1 .{ }^{14}$

interactions, but a discussion of these theories is certainly of interest not only for dualists (Collins 2008). More recently such interactions are discussed in a more general context of top-down causation (Ellis 2016). I will, however, leave this point open, since this discussion is far beyond the scope of this paper.

12 As the derivation of this approach is too involved for the sake of this paper, I refer to the literature. For the underlying concepts see e.g. (Lanczos 1986).

13 There are more of such relations beyond classical mechanics. These are, however, based on symmetries mathematically much more abstract than the ones shown here.

14 The situation is further complicated by the fact that the concept of a well-defined energy cannot be naively transferred beyond classical mechanics. Due to Heisenberg's 
Table 1: Conserved quantities and related symmetries and invariances required for their conservation.

\begin{tabular}{ccc}
\hline conserved quantity & symmetry & invariance against \\
\hline energy & homogeneity of time & translation in time \\
linear momentum & homogeneity of space & translation in space \\
angular momentum & isotropy in space & rotation \\
\hline
\end{tabular}

\section{How could divine intervention work?}

\subsection{Divine intervention}

Looking at stories in the Old and New Testament of the Bible, there are a great variety of examples for divine intervention. In order to relate to the characteristics of mechanical systems described above, I will choose a very simple example of transcendent intervention stated in the New Testament. In the Gospel of Mathew there is a passage that relates to the situation after the crucifixion of Jesus. It is reported that two women wanted to look for the grave of Jesus and experienced an earthquake. This earthquake is reported to be a result of an angel descending from heaven, who moved the stone that was covering the entrance of the grave and sat on it, see Mathew 28,2 . The result of the intervention of the angel is that the women could see that the grave was empty.

uncertainty principle there is an uncertainty in the energy involved in certain quantum mechanical processes. As an example, consider a Laser that emits ultrashort light pulses (e.g. of a duration of only several femtoseconds). In this case, an individual photon can have a substantial uncertainty of its energy and thus wavelength [see e.g. (Giancoli 2010, chap. 39)]. We also encounter a problem in general relativity. Here the concept of energy must be extended and there seems to be no general energy-momentum conservation equivalent to classical mechanics [see e.g. (Bondi 1990) and (Hoefer 2000)]. These findings may suffice to indicate that the naïve picture of classical mechanics that deeply shapes our intuition about the world we live in only represents a small fraction of how the world around and in us functions. 
At this point, I do not want to enter a theological debate about the details or trustworthiness of this particular story, but rather consider how such an event may have proceeded. If we assume that transcendent intervention follows the same path as described above in chapter 2, then the stone is moved by a force according to the laws of classical mechanics, no matter where the force came from. Therefore, if God or angels intervene in the world by applying forces or by changing certain conditions, it appears not to be necessary to violate natural laws. Rather, in the sense described in Fig. 2c, new causes are introduced that lead to results that otherwise would not have happened.

In miracles exceeding effects such as those described above, God may create new entities which he introduces into the world. The very act of creating new entities appears to be outside the scope of natural science. However, once such entities are introduced, everything follows natural processes. ${ }^{15}$ Other kinds of miracles may also concern other domains of physics and it would be interesting to see, whether there are typical patterns accompanying certain types of miracles. The fact that we can only see the effect of divine intervention may feel uncomfortable or threatening. Nevertheless, claiming divine intervention to be unthinkable or impossible seems to be unjustified.

In addition to the discussion above there are a huge number of observations that indicate that such interventions have really happened and are still happening. Craig S. Keener published an extensive systematic investigation of miracles throughout ancient and recent history in and outside Christianity in his two volume book "Miracles" (Keener 2011) and also discusses various explanations and criticism on reports of miracles. He concludes: "Many healing claims involve blindness, inability to walk and even raisings from the dead; other claims involve sudden changes in nature after prayer. Despite some debatable instances, some other cases are fairly clearly extraordinary. It seems to me that to dispute that such phenomena have sometimes occurred is not really possible to open minded people" (Keener 2011, 599). His viewpoint is supported by other contemporary writers, see e.g. Metaxas (2015), who points out, that miracles always have an element

15 The classical example from the New Testament would be the pregnancy of Mary, see Math. 2, $18 f$. 
of message or relation to the individuals experiencing them. As a physicist I would like to add that observations have to be taken seriously and should not be discarded without good reason. This does not mean to discard careful investigation in the trustworthiness of reports on miracles or not to investigate the risk of delusion or fraud. However, a general denial of the occurrence of miracles appears unjustified and unscientific and impedes the openness for new scientific hypotheses and the cross-fertilization of different disciplines of science.

\subsection{The role of probabilistic processes}

Until now I have made no use of probabilistic processes such as quantum mechanics or deterministic chaos with respect to divine intervention. I do not assume that God "hides" behind or depends on quantum indeterminacy or the like. However, chance plays an important role with respect to another aspect: The picture I have developed in the last chapter has significant consequences for the possibility to determine possible causes that led to certain observations. In a purely deterministic world the Laplacian demon described above must be able to derive any previous or future state of affairs. That is, however, not the case in our real world. Take an everyday example: There are many board games that depend on a dice to determine the progress of a player. Suppose you have a documentation of the sequence of each dice thrown, you will be able to reconstruct the course of the game (given that everybody sticks to the rules). If you, however, only see the status of the game at a certain point, you will, in many situations, not be able to reconstruct the sequence of events that led to the current situation. As we do not live in a clockwork universe, it is in many cases not possible, to determine what sequence of events has brought about the result that we now see as an observer. This does not mean that the outcome of processes that include probabilistic mechanisms is always open. The interplay of deterministic and probabilistic mechanisms may well lead to a definite result, as you may observe by playing certain board games right to the end.

As a consequence it may be difficult or even impossible to determine whether a certain event was caused by divine intervention or just by natural processes! Here, the influence of probabilistic processes as described above 
indeed become important. A general discussion of this problem, e.g. including theological arguments, would be far beyond the scope of this paper. However, sometimes an answer may be at hand, as can be seen from the following illustration: Imagine, you believe in God and believe that he can intervene in the world and have (foolish enough) engaged yourself in Russian roulette. If you win, you'll have no financial trouble any more, if you lose, the same is true, but under fairly different circumstances. The other players in the game are atheists who only believe in blind chance. You desperately pray that you will survive, and you do survive and attribute your survival to God's intervention. The others around you believe that this outcome is just good luck. Are you able to decide who is right? But imagine, you prayed - say in the presence of the people who joined you for Russian roulette - that a man who just fell victim to Russian roulette rises from the dead. If this were indeed to happen, could one reasonably assume that this just happened by chance?

As a further result, I conclude therefore that based on the complexity of the causal net described above and the presence of probabilistic processes, the causes that led to a certain effect can often not be uniquely determined. A clear distinction between the effect of transcendent intervention and mere chance may therefore not be possible in many cases of interest.

\section{Conclusions}

The discussion of laws of nature using the framework of classical mechanics shows that the motion of objects is not determined by these laws on their own. To derive equations of motion and their solutions, the forces involved as well as initial and boundary conditions need to be known. Influencing natural (mechanical) processes therefore does not violate laws of nature but only changes the corresponding equations of motion and their solutions by introducing further forces or altering initial or boundary conditions or introducing new entities in the process. Therefore, if God intervenes in the world, new causes are introduced that lead to results that otherwise would not have happened. Further, the objection of energy conservation against divine intervention is not valid, since the total amount of 
energy remains constant only in an isolated system, not in a system that is subject to external influences.

Processes in the world are embedded in a dense net of causes and effects that incorporates deterministic as well as probabilistic mechanisms, the latter being influenced by quantum mechanics and deterministic chaos. In many cases, it may not be possible to uniquely determine the events that caused a certain effect or to identify divine intervention.

\section{Acknowledgements}

I thank Daniel von Wachter, head of the International Academy of Philosophy (IAP) in the Principality of Liechtenstein, for inviting me as a physicist to the conference "Causality, Free Will, Divine Action" in September 2017 in Vienna sponsored by the Templeton Foundation in the framework of the Project "The Openness of the Universe for Free Will and Special Divine Action" and giving me the opportunity to present the ideas discussed here to a philosophical audience.

\section{References}

Alligood, Kathleen T., and James A. Yorke. 2009. Chaos: An Introduction to Dynamical Systems. New York: Springer. https://doi.org/10.1007/b97589

Bondi, Sir Hermann. 1990. "Conservation and Non-Conservation in General Relativity." Proc. R. Soc. Lond. A 427 (1873): 249-58.

https://doi.org/10.1098/rspa.1990.0011

Bultmann, Rudolf. 1960. Neues Testament und Mythologie. Hrsg. von Hans-Werner Bartsch. 4. Aufl. Hamburg: Herbert Reich, Evangelischer Verlag GmbH.

Bussey, Peter J. 2013. "God as a First Cause - a Review of the Kalam Argument." Science and Christian Belief 25 (1): 17-35.

Collins, Robin. 2008. "Modern Physics and the Energy-Conservation Objection to Mind Body Dualism." American Philosophical Quarterly 45 (1): 31-42.

Craig, William Lane. 2002. "The Kalam Cosmological Argument." In Philosophy of Religion. A Reader and Guide, edited by William Lane Craig, 92-113. Edinburgh: Edinburgh University Press.

Dantas, Christine C. 2018. A Note on Norton's Dome. arXiv:1801.01719v2 [physics.class-ph] 29. Jan. 2018.

Eccles, John C. 1994. How the Self Controls its Brain. Berlin, Heidelberg, New York: Springer. https://doi.org/10.1007/978-3-642-49224-2 
Ellis, George. 2016. How Can Physics Underlie the Mind? Top-Down Causation in the Human Context. Berlin Heidelberg: Springer. https://doi.org/10.1007/9783-662-49809-5

Feuerbach, Ludwig. 2016. Das Wesen des Christentums. Altenmünster: Yazzybee Verlag Jürgen Beck. (First published in Leipzig: Otto Wigand 1841.)

Giancoli, Douglas C. 2010. Physics for Scientists and Engineers with Modern Physics. $3^{\text {rd }}$ Ed. München, San Franzisco et al.: Pearson.

Härle, Wilfred, ed. 2007. Grundtexte der neueren evangelischen Theologie. 3. Aufl. Leipzig: Evangelische Verlagsanstalt.

Hawking, Stephen, and Leonard Mlodinow. 2010. The Grand Design-New Answers to the Ultimate Questions of Life. London: Transworld Publishers.

Hoefer, Carl. 2000. "Energy Conservation in GRT." Stud. Hist. Phil. Mod. Phys. 31 (2): 187-99.

Keener, Craige S. 2011. Miracles. The Credibility of the New Testament Accounts. Grand Rapids: Baker Academic.

Lanczos, Cornelius. 1986. The Variational Principles of Mechanics. $4^{\text {th }}$ Ed., Dover Books on Physics and Chemistry. New York: Dover Publishing.

Laplace, Pierre Simon. 1814. Essai philosophique sur les probabilities. Paris.

(Newly printed Brussel 1967.)

Laraudogoitia, Jon Pérez. 2013. "On Norton's Dome." Synthese 190 (14): 2925-41. https://doi.org/10.1007/s11229-012-0105-z

Larmer, Robert A. 2009. "Divine Agency and the Principle of the Conservation of Energy." Zygon 44 (3): 543-57. https://doi.org/10.1111/j.14679744.2009.01015.x

Larmer, Robert A. 2014. The Legitimacy of Miracle. Maryland: Lexington Books. Lewis, Clive Staples. 1947 [2016]. Miracles. London: William Collins.

Krauss, Lawrence M. 2012. A Universe from Nothing. New York: Free Press, Simon and Schuster Inc.

Mackie, John Leslie. 1982. The Miracle of Theism: Arguments for and against the Existence of God. Oxford: Clarendon Press.

Metaxas, Eric. 2015. Miracles. New York: Dutton.

Ney, Alyssa, and David Z. Albert, eds. 2013. The Wave Function-Essays on the Metaphysics of Quantum Mechanics. Oxford: Oxford University Press.

Norton, John D. 2008. "The Dome: An Unexpected Simple Failure of Determinism." Philosophy of Science 75 (5): 786-98. https://doi.org/10.1086/594524

Schleiermacher, Friedrich. 1969. Über die Religion. Reden an die Gebildeten unter ihren Verächtern. Stuttgart: Reclam. (First published in Berlin: Unger 1799.) von Meckenstock, Günther, Andreas Arndt, Jörg Dierken, Lutz Käppel, and Notger Slenczka, eds. 2011. Friedrich Schleiermacher: Kritische Gesamtausgabe. Berlin: De Gruyter. 
von Wachter, Daniel. 2015. "Miracles Are Not Violations of the Laws of Nature Because the Laws Do Not Entail Regularities." European Journal for Philosophy of Religion 7 (4): 37-60. https://doi.org/10.24204/ejpr.v7i4.86

Wilckens, Ulrich. 2017. Theologie des Neuen Testaments. Band III Historische Kritik der historisch-kritischen Exegese. Göttingen: Vandenhoeck und Ruprecht. 